\title{
A Successful Reconstructive Case of Tibia Hemimelia in Syndromic Child
}

\author{
Norzakiah Abu Mansor Matardiah ${ }^{1 *}$, Nor'Ashikin Johari ${ }^{2}$ and Mohd Azli Abdul Hamid ${ }^{3}$ \\ ${ }^{1}$ Orthopaedic Department \& Traumatology, Hospital Tuanku Fauziah, 01000 Kangar Perlis Malaysia \\ ${ }^{2}$ Orthopaedic Department, Women and Children Hospital, 50586 Kuala Lumpur, Wilayah Persekutuan Kuala Lumpur, Malaysia \\ ${ }^{3}$ Orthopaedic \& Spine Unit, Prince Court Medical Centre, 39, Jalan Kia Peng, Kuala Lumpur, 50450 Kuala Lumpur, Wilayah Persekutuan \\ Kuala Lumpur, Malaysia
}

*Corresponding author: Norzakiah Abu Mansor Matardiah, Orthopaedic Department \& Traumatology, Hospital Tuanku Fauziah, 01000 Kangar Perlis Malaysia

\section{ARTICLE INFO}

Received: 幽 July 08, 2019

Published: 畵 July 18, 2019

Citation: Norzakiah Abu Mansor M, Nor'Ashikin J, Mohd Azli A. A Successful Reconstructive Case of Tibia Hemimelia in Syndromic Child. Biomed J Sci \& Tech Res 19(5)-2019. BJSTR. MS.ID.003352.

\section{ABSTRACT}

Tibia hemimelia is a very rare congenital disorder. It is characterized by either absent or deficient of the tibia in relatively normal fibula. Therefore clinically; the affected leg will appear short and the foot will be in equino-varus position. It is infrequently associated with other malformations. We report a case of a syndromic child with unilateral tibia hemimelia, whom underwent series of reconstructive procedures and succeed obtaining good functional outcome.

Keywords: Tibia Hemimelia; Absent Tibia; Equino-Varus; VACTERL Syndrome

\section{Introduction}

Congenital long bone deficiency is very rare, so as tibia hemimelia, which is reported to be one in one million [1]. The first reported case of tibia hemimelia is in 1861. Tibia hemimelia is usually appears as a short and deformed leg with knee and ankle involvement. The knee involvement may present as absent of extensor mechanism, multidirectional ligamentous laxity or flexion contracture. The ankle typically appears varus and equinous, whereas the foot will be in adduction and supination. There are reported associated syndromes and anomalies such as Werner syndrome, tibia hemimelia diplopodia syndrome, and tibia hemimelia split hand and foot syndrome. Some cases of tibia hemimelia are genetically transmitted as autosomal dominant or recessive, whereas others are sporadic. Jones classification is simple widely used radiographic classification, and further modified by Kalamchi and Dawe in 1985 (Table 1). Recent classification by Paley in 2003 is also based on Jones classification [2]. These classifications play a role to determine an appropriate intervention in terms of limb salvage procedure or amputation. We described a case of VACTERL association (vertebral defects, anal atresia, cardiac defects, trachea-esophageal fistula, renal anomalies, and limb abnormalities) with unilateral tibia hemimelia that successfully reconstructed with good functional outcome.
Table 1: Jones Classification of Tibia Hemimelia.

\begin{tabular}{|r|c|}
\hline Type I- Ia & No visible tibia \\
Ib & $\begin{array}{c}\text { Hypoplastic distal femur epiphysis } \\
\text { Normal distal femoral epiphysis ossification (possible } \\
\text { cartilaginous proximal tibia) }\end{array}$ \\
\hline Type II & Distal tibia deficiency \\
\hline Type III & Proximal tibia deficiency \\
\hline Type IV & Shortened tibia with distal tibia-fibula diastasis \\
\hline
\end{tabular}

\section{Case Report}

We present a 12 years old Chinese boy, who was delivered full term via elective caesarean section. He was diagnosed with VACTERL association. He had ano-rectal fistula, and tracheaesophageal fistula which were repaired. He had unilateral lobster hand, which is in good function. He presented with short unilateral leg, equino-varus position of the ipsilateral ankle and the foot was in correctable adduction and supination. His quadriceps mechanism of right knee was present. At birth, he had five centimetre of limb length discrepancy. Radiograph of the leg revealed presence of proximal tibia with absence of distal tibia, Type II according to Jones classification (Figure 1). The first operation over right leg was done when he was two years of age. He underwent centralization 
of the fibula, correction of right foot and stabilization of the ankle (Figure 2). The synostosis of proximal tibia to fibula was held with intramedullary retrograde $\mathrm{K}$ wire from calcaneum. It was meant to also stabilize the corrected ankle. Full length plaster cast is applied to maintain the fixation. However, it was complicated with fibrous union over the attempted tibio-fibular synostosis. Subsequently he underwent excision of fibrous union and screw fixation, and finally the union achieved. He had series of lengthening procedures to correct the limb length inequality.

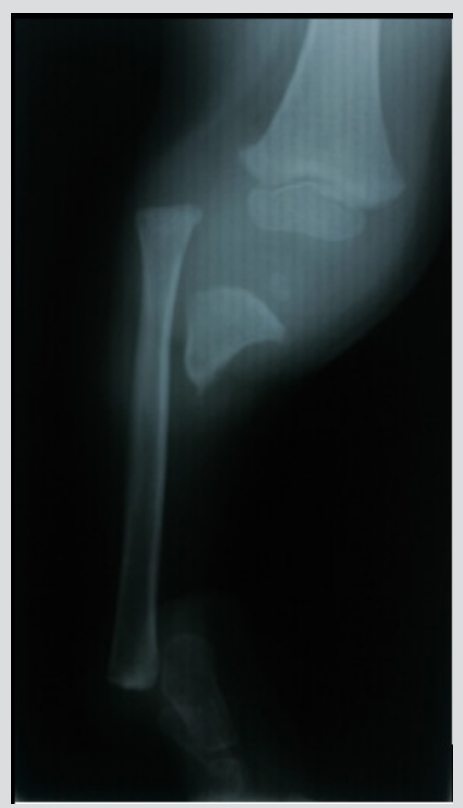

Figure 1: Tibia hemimelia with presence of proximal tibia, and distal tibia is not seen.

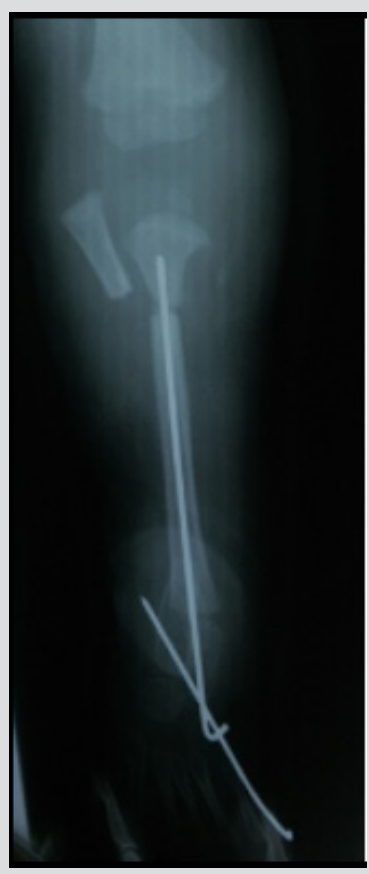

Figure 2: Post-operative radiograph after centralization of fibula and ankle.
He had his first lengthening procedure with ring fixator at the age of sixth years old, with seven centimetres of limb discrepancy, aimed at five centimetre lengthening. An extension osteotomy of right ankle was done simultaneously. Following the procedure he achieved improvement of residual 3 centimetres decaprenyl. At the age of 10 years old, he had progressive discrepancy of 5 centimetres. He agreed for another lengthening procedure with uniplanar external fixator. He did not experience any complication during these two lengthening procedures. His knee range of movement is 10 degrees to 120 degrees. Functionally, he is able to walk in plantigrade foot with residual two centimetres shortening at the age of 12 years old (Figures $3 \& 4$ ).

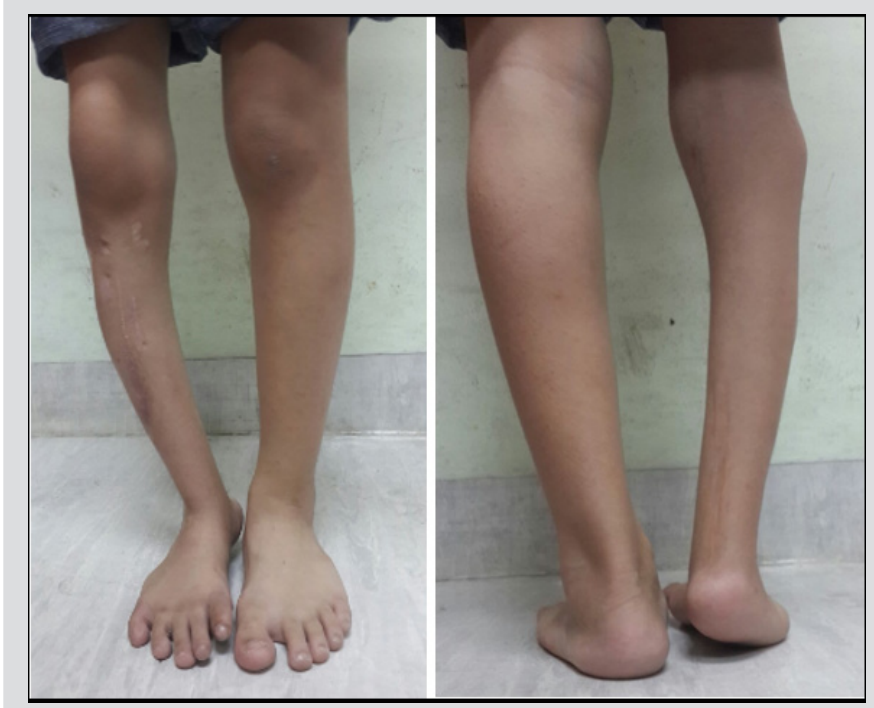

Figure 3: Photograph of both legs shows almost equal length and plantigrade foot.

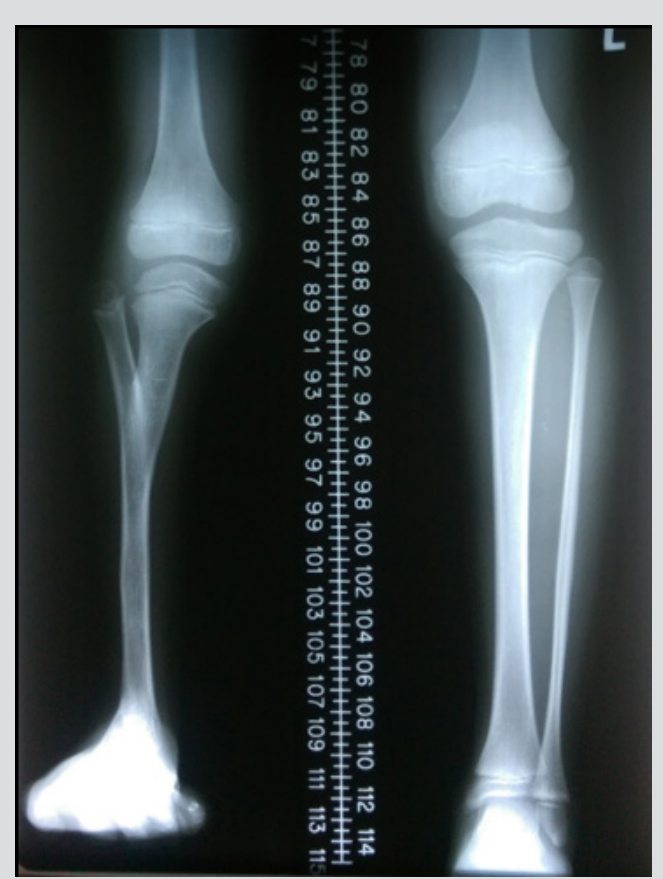

Figure 4: Radiograph of both lower limbs after final correction showed two centimetres of discrepancy. 


\section{Discussion}

The management of congenital long bone deficiency is rather challenging as few factors need to be considered. In complete tibia hemimelia (Jones type Ia), primary amputation via knee disarticulation will provide good functional outcome. However, in incomplete tibia hemimelia, where there is presence of extensor mechanism (Jones type Ib and II), limb salvage procedures may benefit the patients. However, the child might need series of procedures to reconstruct and lengthen the affected limb. The stability of the foot is also another factor to look into as the management of unstable ankle may varies from primary amputation, arthrodesis and reconstruction. In type IV Jones classification, early ankle disarticulation is the best option to get good functional outcomes. In this case, the patient has extensor mechanism of the involved tibia, of Jones classification type II. Therefore, reconstruction was a wise option even though he had marked limb length inequality at birth. Hassan et al. [3] had almost similar management as for this patient pertaining to type II tibia hemimelia. However, he considered patient's age as an important factor to embark the patients into surgical treatment. The tibiofibular synostosis was done after three years of age in order to get good bone stock for successful fusion. In our case, he had a fibrous union at the synostosis site which required surgical excision of the fibrous tissue and screw fixation of the tibio-fibular junction. Youssef et al. [4] performed proximal tibiofibular fusion as a second stage procedure after ankle centralization. Foot deformity in tibia hemimelia also should be addressed properly along with tibia reconstructive procedure.

\section{ISSN: 2574-1241}

DOI: 10.26717/BJSTR.2019.19.003352

Norzakiah Abu Mansor M. Biomed J Sci \& Tech Res

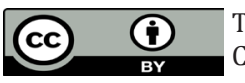

This work is licensed under Creative Commons Attribution 4.0 License

Submission Link: https://biomedres.us/submit-manuscript.php
Youssef et al. [4] performed soft tissue release of the foot, and centralization of the ankle with preservation of the distal fibular physis as his first stage treatment. As for this case, stabilization of the ankle done with $\mathrm{K}$ wire and maintained with plaster cast, was done simultaneously during tibial procedure. He achieved fairly good functional outcome with painless unaided gait, almost plantigrade foot and reasonable knee range of motion. He has two centimetres limb length discrepancy with expected total length inequality is four centimetres at maturity [5]. The options for limb length discrepancy include growth modulation procedure on contralateral normal limb, or another lengthening procedure for his right tibia. In conclusion, the management of tibia hemimelia is mainly surgical correction or reconstruction. Whenever possible, limb salvage procedure is wisely to take into consideration.

\section{Conflict of Interest}

None.

\section{References}

1. Javid M, Shahcheraghi GH, Nooraie H (2000) Ilizarov lengthening in centralized fibula. J Paediatric Orthop 20(2): 160-162.

2. Paley D, Chong DY (2016) Tibia Hemimelia. Paediatric Lower Limb Deformities 24: 455-481.

3. Hassan El-Barbary (2003) Management of Tibia Hemimelia. Pan Arab J Orth Trauma 7(2):125-137.

4. Youssef Ahmed, Amin Abdel Razek (2014) Staged Soft Tissue, Bony and Ilizarov Procedures for Correction of Leg and Foot Deformities in Tibial Hemimelia. Clin Res Foot Ankle 2(2): 1-5.

5. Prashanth M, Srinivasan V, Satish JK, Kamakshi D (2014) A Case of Unilateral Tibia Hemimelia with Unilateral Radial Club Hand and Constrictive Band. Journal of Evolution of Med and Dent Sci 24(3): 67226725.

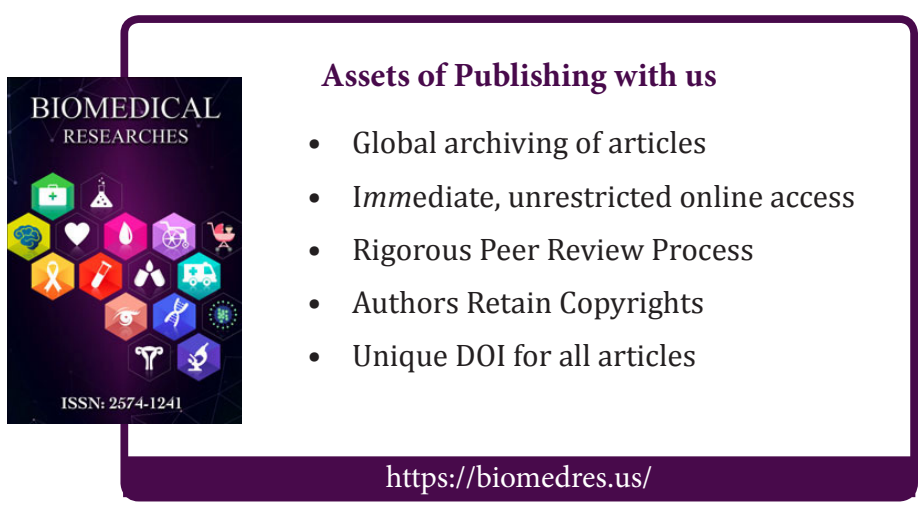

